\title{
IMPROVING THE LAND SURFACE GENERAL DROUGHT INDEX MODEL
}

\author{
Alfred Homère Ngandam Mfondoum ${ }^{* 1,2}$, Paul Gérard Gbetkom ${ }^{3}$ Ryan Cooper ${ }^{4}$, Sofia Hakdaoui ${ }^{5}$, \\ Mamane Barkawi Mansour Badamassi ${ }^{6}$
}

1 StatsN'Maps, Private Consulting Firm, Dallas, Texas 75287, USA. stats.n.maps.expertise@ gmail.com

2 Department of Geography, University of Yaoundé I, Yaoundé, Cameroon. Alfred.homere@ gmail.com

${ }^{3}$ Department of Geography, University of Aix-Marseille, Marseille, France. Paul-gerard.gbetkom@etu.univ-amu.fr

${ }^{4}$ Erik Jonsson School of Engineering and Computer Science, University of Texas in Dallas, Dallas, Texas 75080, USA. Rdc190001@utdallas.edu

${ }^{5}$ Earth Observation department, Geo-Biodiversity and Natural Patrimony Laboratory, Geophysics, Natural Patrimony and Green Chemistry Research Center, Scientific Institute, Mohamed V University, Rabat, Morocco. s.hakdaoui@gmail.com

${ }^{6}$ Laboratory of Botanic, Mycology and Environment, Mohammed V University, Rabat, Morocco. barkawimansour@yahoo.fr

Keywords: Drought, Remote Sensing, Spectral index, Improved Land Surface General Drought Index, Vegetation Moisture Index, Normalized Difference Soil Drought Index, Landsat, Semi-arid regions.

\begin{abstract}
Drought affects all human activities and ecosystems. Nearly 40 percent of the world's population inhabit Drylands, and they depend on agriculture for their food, security and livelihoods. Among the remote sensing indices developed, the Land Surface General Drought Index (LSGDI) was recently proposed. This paper proposes an improved model of LSGDI to face the issue of drought in semi-arid and arid regions. The experiment was conducted for the Maga's floodplain, in NorthCameroon. The method uses satellite images of Landsat in 1987, 2003 and 2018, for January and March or April, corresponding to the middle and the end of the dry season. A Vegetation Moisture Index (VMI) and a Normalized Difference Soil Drought Index (NDSoDI) are both developed. On an orthogonal plan, their projections give a drought line that expresses the improved LSGDI (LSGDI2) as the root sum square of the NDSoDI and the VMI. The LSGDI2 results are ranged in [0.09-0.14] interval, which is used to define the threshold and ease the qualifiers for drought classes. The visual patterns easily match the sandy areas of the original Landsat images with the highest values, while the vegetation and water areas match the lowest values. Compared with the LSGDI and Second Modified Perpendicular drought Index (MPDI1), the new index reflectance values are higher. Finally, although LSGDI2 curve's evolution follows the NDSoDI one at 94\%, the new spectral index values depends on the both components, helping to map highest values of drought and moisture in Maga's floodplain, for a sustainable rice culture expansion.
\end{abstract}

\footnotetext{
* Corresponding author (stats.n.maps.expertise@gmail.com)
} 


\section{INTRODUCTION}

Drought refers to an extended period, i.e. a season, a year, or several years, of deficient rainfall, relative to the statistical multi-year average for a region (Graham, S. 2000). Although there are dozens of definitions covering meteorological and hydrological aspects, this study addresses the agricultural effects of drought, in terms of the risk of low soil moisture and crop needs in the semiarid regions. This affects all human activities and ecosystems, and more than 2 billion people, nearly 40 percent of the world's population (White and Nackoney, 2003), inhabit Drylands. These populations depend on agriculture for their food, security and livelihoods. Over the years, Earth Observation (EO) sciences have been efficient in spatializing drought areas. Spectral indices are among the most important approaches.

From the vegetation moisture view, the Normalized Difference Vegetation Index (NDVI) and its derivatives such as the Soil Adjusted Vegetation Index (SAVI) and the Modified Adjusted Vegetation Index (MSAVI), based on the red and near infrared (NIR) wavelengths, were developed to monitor the vegetation cover and stage of growth. The Normalized Difference Water Index (NDWI) (Gao, 1996), the Anomaly Vegetation Index (AVI), the Vegetation Condition Index (VCI) (Kogan, F., 1995), and the Vegetation Health Index (VHI) (Kogan, F., 1997), help with assessing vegetation stress and health. Further, the Normalized Difference Drought Index (Gu, Y. et al., 2007) was used to assess the covered land surface dryness.

From the perspective of soil drought or moisture, the Normalized Multi-band Drought Index (NMDI) (Wang, L. and Qu, J.J., 2007) and the Perpendicular Drought Index (PDI) (Qin, Q. et al., 2008) were developed. The PDI was modified through the MPDI (Ghulam A., et al., 2008) and the MDPI1 (Li, Z. and Tan, D., 2014).

The main goal of this paper is to assess the land surface drought, through another spectral model that assesses the covered and the uncovered land dryness. Its gives a second technical approach of the Land Surface General Drought Index, LSGDI (Ngandam Mfondoum and Gbetkom, 2019), for sustainable agriculture expansion in arid and semi-arid regions.

\section{METHODOLOGY}

\subsection{Research location}

The research was conducted on the site of Maga's floodplain, located between latitudes $10^{\circ} 37^{\prime}-10^{\circ} 54^{\prime} \mathrm{N}$, and longitudes $14^{\circ} 40^{\prime}-15^{\circ} 10^{\prime} \mathrm{E}$, in northern-Cameroon (Central Africa). It is an artificial floodplain extended on 1560 hectares and more than 200000 hectares with its surroundings, where a project of irrigated rice cultivation was launched in 1985 to promote national production. According to the national bioclimatic map, Maga's floodplain belongs to the Sudano-sahelian or semi-arid zone (Figure 1). Yearly, the rainfall is around $500 \mathrm{~mm}$, and temperatures vary between $15^{\circ}$ and $41^{\circ}$ Celsius. Natural vegetation is made of savannah that exposes the soil. The soil is loamy, clay and alluvial, characterized by sediments deposits. Several types of soil degradation have been identified, modelled and mapped (Ngandam Mfondoum, A.H. et al., 2016; Ngandam Mfondoum, A.H. and Gbetkom, P.G., 2019; Gbetkom, P.G. et al., 2019). However, there is still a need for EO support to anticipate the risk of increased silting, salinization and sodisation during the irrigated rice project's expansion planned by Cameroon's government.

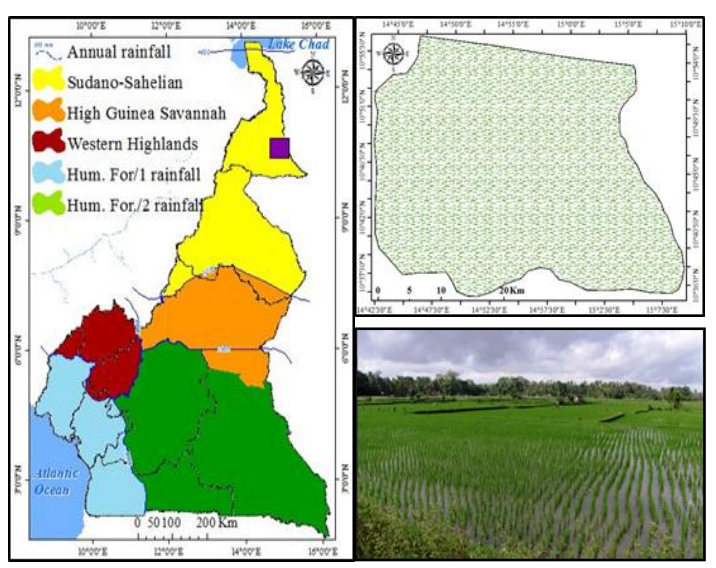

Figure 1. Maga's Floodplain, the study area

\subsection{Data acquisition and pre-processing}

The data used is from the Landsat sensors Thematic Mapper (TM) of 1987, Enhanced Thematic Mapper plus (ETM+) of 2003 and Operational Land Imager (OLI) of 2018 (Table1). They were downloaded from the United States Geological Survey website and displayed under false colour composite SWIR2-NIR-Red (Figure 2).

Table 1. Landsat images information

\begin{tabular}{|c|c|c|c|c|c|c|}
\hline 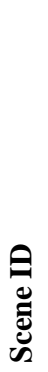 & 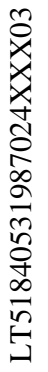 & 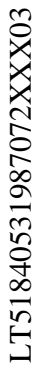 & 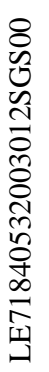 & 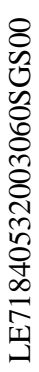 & 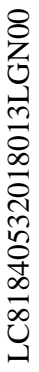 & 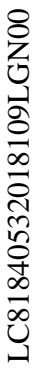 \\
\hline 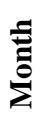 & 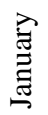 & $\begin{array}{l}\frac{\sigma}{0} \\
\stackrel{\Xi}{Z}\end{array}$ & 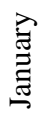 & $\frac{\tilde{J}}{\stackrel{\Xi}{\Xi}}$ & $\underset{\stackrel{\Xi}{\Xi}}{\stackrel{\Xi}{\Xi}}$ & $\begin{array}{l}\text { 竞 } \\
\end{array}$ \\
\hline 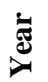 & \multicolumn{2}{|c|}{$\hat{\infty}$} & \multicolumn{2}{|c|}{ ঠి } & \multicolumn{2}{|c|}{$\underset{\sim}{\infty}$} \\
\hline
\end{tabular}




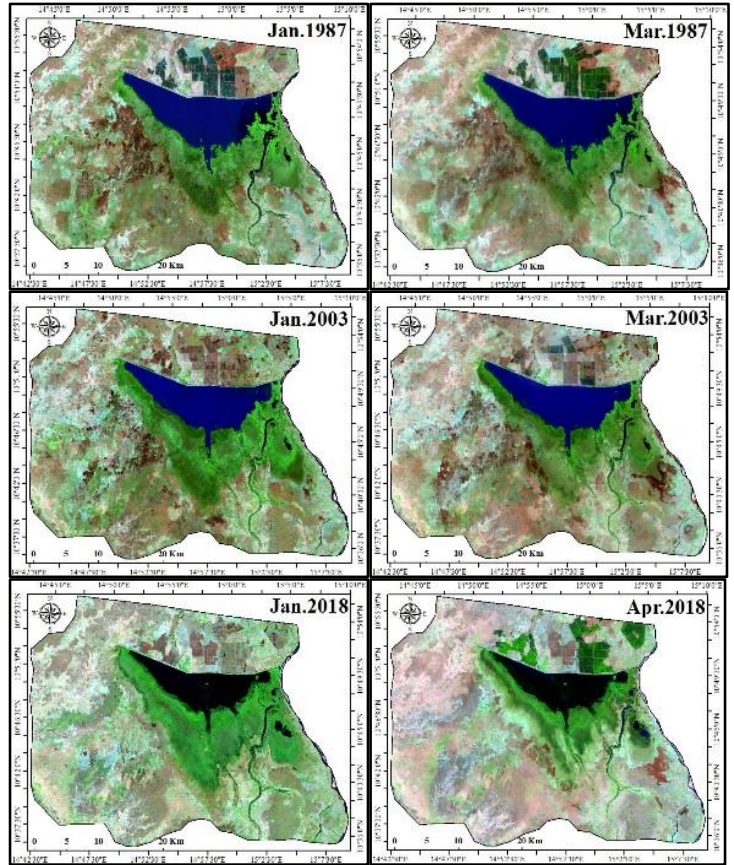

Figure 2. Landsat images in SWIR2-NIR-Red colour

Pre-processing help to minimize the effects of sensor, solar, atmospheric and topographic distortions. The images used are Level-1 products, which are delivered as digital numbers, DNs. Bands blue, green, red, near infrared, and both shortwave infrared were stacked. Applying the Cosine Solar TAUZ (COST) radiometric calibration model to the stacked image, the DNs were converted from at-sensor radiance to top-of-atmosphere (TOA) reflectance via solar correction, and rescaled from 64-bit to 8-bit. Atmospheric corrections and haze reduction have helped to remove other noises and then approximate values of surface reflectance. The last step concerned the topographic correction to lower altitude artifacts.

\subsection{Experiment design}

Ngandam Mfondoum and Gbetkom (2019) assume that balancing the moisture of the vegetated area with the dryness of the bare soil, is necessary to learn about the general drought retrieved from remote sensing techniques. They propose the Land Surface General Drought Index (LSGDI) as a normalized difference written as follows:

$$
\text { LSGDI }=1-\frac{\text { NDSoDI-VMI }}{\text { NDSoDI+VMI }}
$$

Where the NDSoDI is the Normalized Difference Soil Drought Index and the VMI is the Vegetation Moisture Index. The subtraction of the normalized difference from 1 is suggested in order to: $\boldsymbol{i}$ ) invert the values of soils from lower to higher values in the VMI; ii) keep highest values of the soil drought in the NDSoDI.

\subsubsection{The Vegetation Moisture Index (VMI)}

This index utilizes as entries the NDWI (Gao, B-C., 1996) and the SAVI (Huete, A.R., 1988).

$$
\begin{aligned}
& \text { NDWI }=\frac{\text { NIR-SWIR1 }}{\text { NIR+SWIR1 }} \\
& \text { SAVI }=\frac{(\text { NIR-Red })}{(\text { NIR+Red+L) }} *(1+\mathrm{L})
\end{aligned}
$$

The NDWI is sensitive to changes in liquid water content and in spongy mesophyll of vegetation canopies (Gao, 1996). Its values usually exhibit a quicker response to drought conditions than NDVI (Gu et al., 2007). In sparse vegetation cover conditions characterizing semiarid zones, the SAVI is most suitable to assess vegetation cover and stages of growth and for adjusting the background soil reflectance through constant $L$ value.

Spectral space plot between the NDWI and the SAVI for the main land cover categories, i.e. sandy soil, other soil, water body and rice crops, shows that they are highly correlated by the vegetation (Figure3). However, while the other objects values are decreasing for the SAVI in the order [Sandy soil-Other soil-Water body], for the NDWI, the order is [Water body-Sandy soil-Other soil].

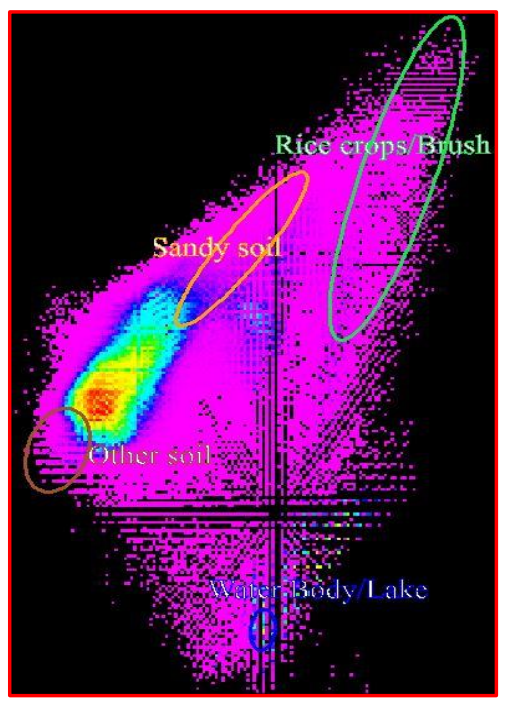

Figure 3. The spectral relation between NDWI (X axis) and SAVI (Y axis)

GAO (1996) notices that the soil background and snow cover effects are not masked in the NDWI. Therefore, to keep only the vegetation moisture as high values, the water body's values would be lower by subtracting the blue wavelength values from the sum of the SAVI and the NDWI, as follows:

$$
\mathrm{VMI}=\frac{(\mathrm{NDWI}+\mathrm{SAVI})-\text { Blue }}{(\mathrm{NDWI}+\mathrm{SAVI})+\text { Blue }}
$$

When visually compared to the NWDI and the SAVI, the VMI shows more efficiency in keeping vegetation moisture, lowering surface water, and being more sensitive to vegetation, soil features and sediments deposits at the lake's bottom (Figure 4). 


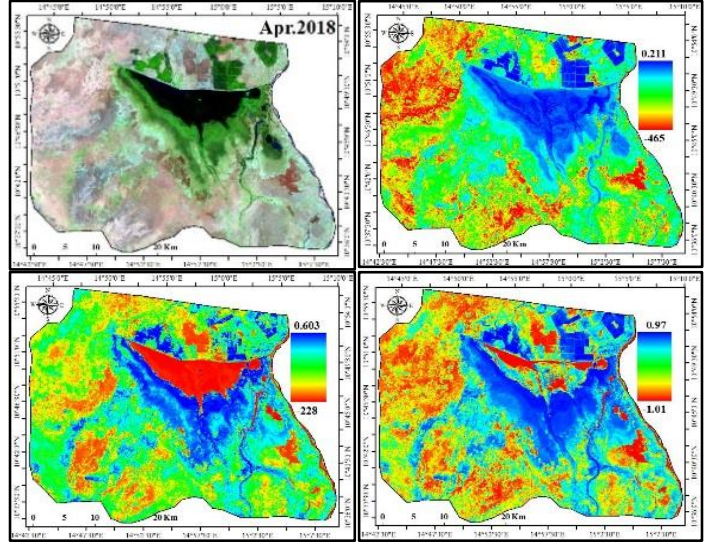

Figure 4. Visual patterns. Left-right and top-down: Landsat image, NDWI, SAVI and VMI.

\subsubsection{The Normalized Difference Soil Drought Index (NDSoDI)}

Its computation is based on the spectral behaviour of soils according to their moisture. Lobell and Asner (2002) have demonstrated that the soil reflectance varies according to its moisture through the following exponential model:

$$
R=f \times R_{d r y}+(1-f) \times R_{d r y} \exp (-c \times \theta)
$$

Where $\mathrm{R}$ is the soil reflectance at a particular wavelength, $\theta$ is the volumetric soil water content, $R_{\text {dry }}$ is the reflectance of dry soil (at $\theta=0.0$ ), c describes the rate of soil reflectance change with moisture, and $\mathrm{f}$ is the ratio of the saturated to dry reflectance.

A local spectral library was constructed. Figure 5 shows the land surface reflectance variation of the four training samples types of soils according to their predicted moisture.

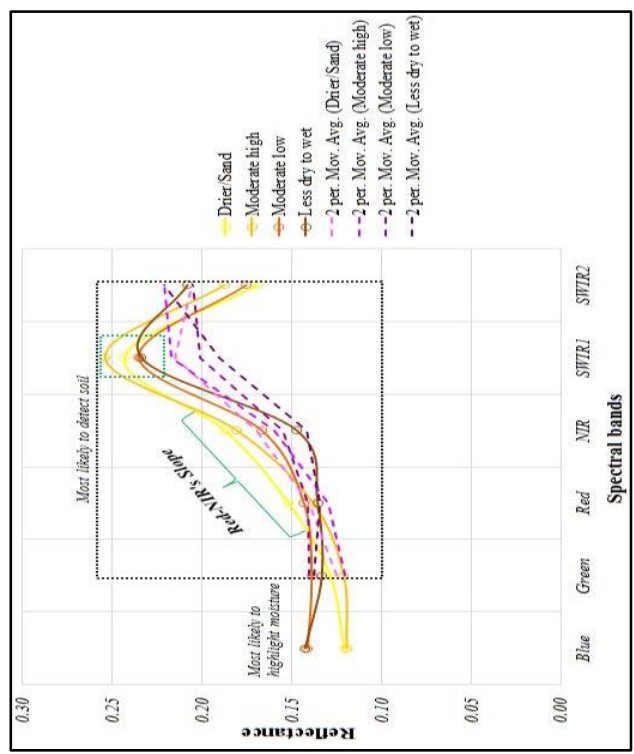

Figure 5. Reflectance of the four types of soils dryness

The evolution the "two periods" moving average trend lines built for each type of soil delimits the suitable electromagnetic spectrum wavelengths between the middles of the green and the SWIR2 (black square), while the most suitable is the SWIR1 (green square). These lines also highlight the Red-NIR's slope (green brace) as the transition between the first period going from the SWIR2 to NIR and the second period going from the NIR to the green. From the green to the blue, there is no trend change, signs of end of the slope.

Complementary analysis is made through the reflectance space between bands, sampling the four major land cover objects, i.e. sandy soil, other soils, water body and vegetation. Plots between the blue, the red and the SWIR1 bands in the six periods of the study. The example of April 2018 (Figure6) let shows that, in the blue-red feature space, the decreasing correlation order is [Sandy soil-Other soil-Water body-Rice crops], water body and rice crops being too close in values. The blueSWIR1 and the red-SWIR1 plots show the same order, i.e., [Sandy soil-Other soil-Rice crops-Water body].
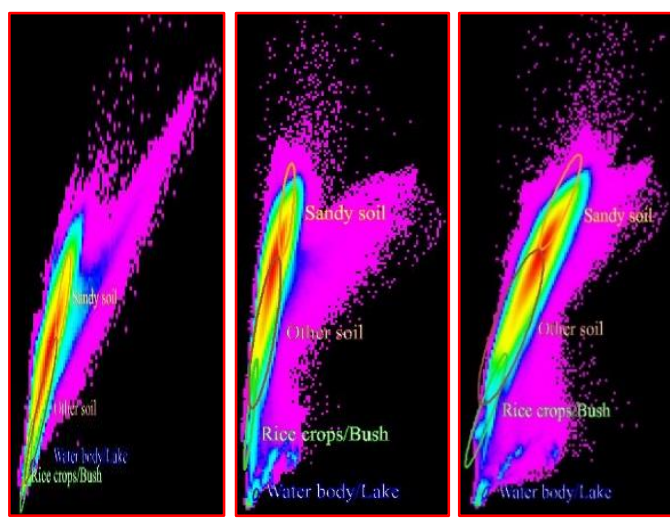

Figure 6. Features spaces. Left's plot - Blue (X axis) Red ( $Y$ axis); Middle's plot - Blue ( $X$ axis) SWIRl ( $Y$ axis); Right's plot - Red (X axis) SWIR1 (Y axis)

The reflectance differences among water and sandy soils spectral curves are also to be noticed between in the three concerned wavelengths (Figure 7).

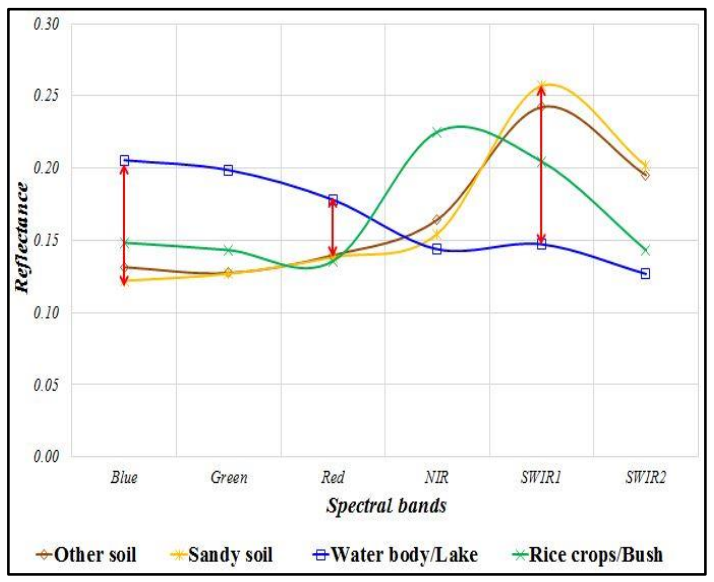

Figure 7. Reflectance curves for April 2018 
From these views, it is assumed that, sand and soil features would be highlighted, when adding the red and SWIR1 bands, showing a strong positive convergence along a soil slope. The moisture would be assessed by subtracting the blue band and adjusting the water and soil reflectance values. The adjustment factor's values are settled according to the reflectance difference between the sand's spectral curve, which has the highest bare soil reflectance, and the water body's curve, in the blue, the red and SWIR1 bands for each month

Table 2. Adjustment factor's values $(L)$

\begin{tabular}{|l|l|l|l|l|l|l|}
\hline \multicolumn{2}{|l|}{1987} & \multicolumn{2}{l|}{$\mathbf{2 0 0 3}$} & \multicolumn{2}{l|}{$\mathbf{2 0 1 8}$} & \multirow{2}{*}{ Average } \\
\cline { 1 - 5 } Jan. & Mar. & Jan. & Mar. & Jan. & Apr. & \\
\hline 0.49 & 0.38 & 0.47 & 0.44 & 0.23 & 0.24 & 0.375 \\
\hline
\end{tabular}

The average for the six periods is $0.375 \approx 0.4$. However, considering the high difference values between years, the $L$ value of each month is used. The NDSoDI is then written as follows:

NDSoDI $=\frac{(\text { Red }+ \text { SWIR1 })-\text { Blue }}{(\text { Red }+ \text { SWRI } 1)+\left(\text { Blue }+\sum L\right)}\left(1+\sum L\right)$

Where $\sum L$ is the sum of the differences between the sandy soil and the water body curves in the blue, red and SWIR1 bands. The highest values describe soil dryness and the lowest values its moisture, as shown on figure 8 .

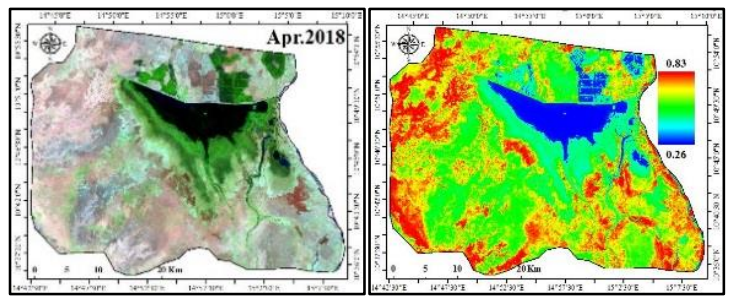

Figure 8. NDSoDI visual patterns

Accordingly, this index can be called the Soil Adjusted Moisture Index (SAMI) when the lowest values are to be considered.

\subsubsection{The improved Land Surface General Drought Index (LSGDI2)}

From the above reasoning, it is hypothesized that adding the drought of the land vegetated area with the one of the bare soil will provide better information regarding general droughts. When combining the VMI and NDSoDI spectral space, dry and wet surfaces can be represented on $x-y$ orthogonal axes to locate the LSGDI2 (Figure 9).

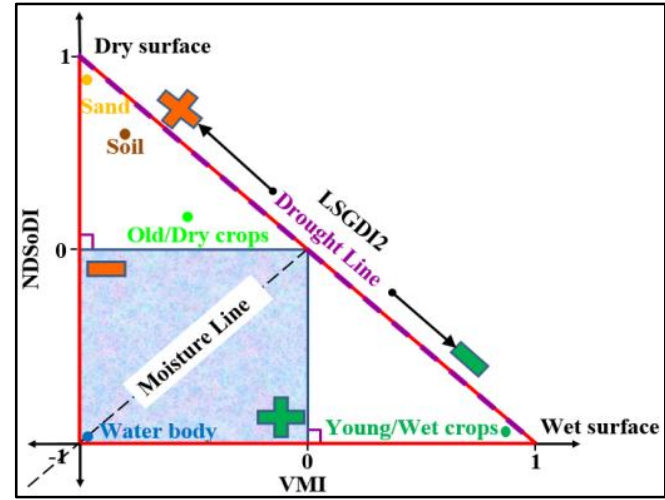

Figure 9. LSGDI2 on the VMI-NDSoDI orthogonal plan

The moisture square includes the water body in both VMI and NDSoDI lower values, and its diagonal, the moisture line, separates two triangles representing the both indices areas of influence. The value needed equals to the triangles right angles projection, named the drought line, and corresponding to the LSGDI2. According to Pythagorean Theorem, it should be expresses as the square root of sum of squares of the NDSoDI and the VMI, such as:

LSGDI2 $=\sqrt{\mathrm{NDSoDI}^{2}+\mathrm{VMI}^{2}} * 0.1$

The value 0.1 helps adjusting the values below 1 , to ease the interpretation of the results.

\section{RESULTS AND DISCUSSIONS}

\subsection{Dynamic ranges and visual patterns appraisal}

The LSGDI2 global range dynamics are between 0.097 and $0.137 \approx 0.14$ for the studied period (Figure 10). The difference with the LSGDI is that from the obtained values, it is easy to affect qualifiers to classes of drought. Therefore, the resulting image was reclassified and the thresholds were defined, using the five descriptors from Palmer's drought severity classification: [Exceptional drought - Extreme drought - Severe drought-Moderate drought - Abnormally drought]. With maximums of 0.137 and 0.134 respectively in January and March, 2003 was the drier year. It could be predicted that all values from 0.13 and above $(\geq 0.13)$ are classified "exceptional drought", and those below 0.1 (0.9) are classified "abnormally drought" or moist areas.

Moreover, the visual patterns compared with the original Landsat images demonstrate that highest values correspond to sand and lower values to water body and rice crops (Figure 10). 


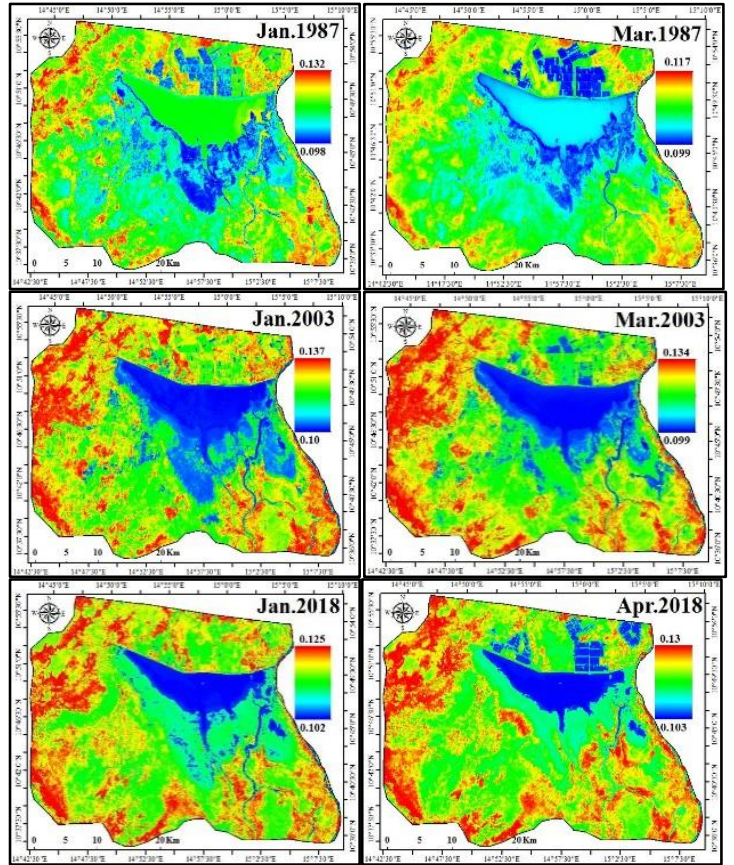

Figure 10. Visual patterns of the LSGDI2

\subsection{Reflectance efficiency and its statistical impact}

A comparison was run with the LSGDI and the MDPI1 (Li, Z. and Tan, D., 2014). As reminding, MDPI1 processing also assesses the soil and vegetation moisture/drought in one algorithm:

$$
\mathrm{MDPI} 1=\sqrt{\mathrm{PDI}^{2}+\mathrm{PVI}^{2}}
$$

The three indices values were resampled in the interval [0 - 1] to ease the comparison. After that, fifteen (15) pixels were sampled on each stretched image, with correspondence in all the five (05) classes of drought. It appears that LSGDI2 reflectance neatly enhances those given by the MDPI1 and LSGDI (Figure 11).

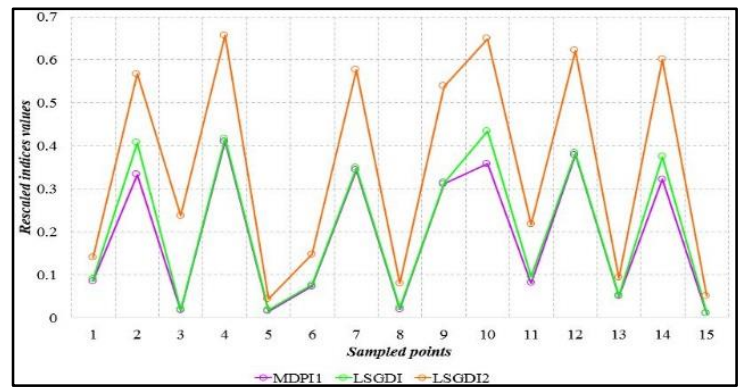

Figure 11. Reflectance of the three indices for April 2018

A statistical analysis with each class confirms the LSGDI2 efficiency in detecting drought, by varying comparatively to visual patterns interpretation and the two others indices (figure 12). For instance, its "Abnormally drought" class areas for January 2003 and April 2018, are respectively 1/6 (16716 ha / 92976 ha) and 1/7 (9658 ha/69257 ha), less than LSGDI ones. Concerning the MDPI1, its areas for the "Exceptional drought" class values has been almost the same, i.e. around 52680 hectares during the six periods (Figure 12).

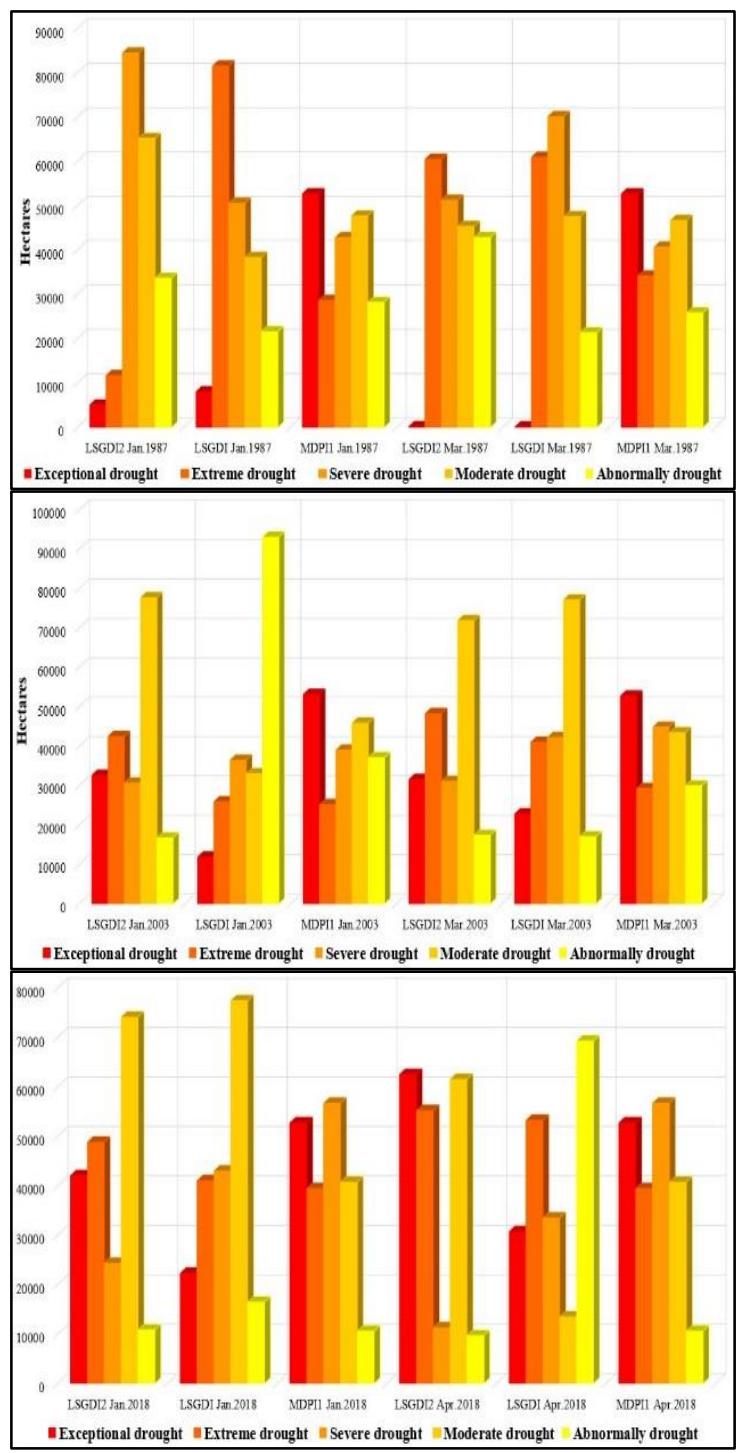

Figure 12. Compared areas statistics for the three indices

\subsection{Drought and moisture informative analysis}

LSGDI2 values come from both the NDSoDI and VMI. It appears on fifteen (15) sampled points that LSGDI2 curve is distinct from its two components' ones (Figure13). Therefore, they both contribute to the model.

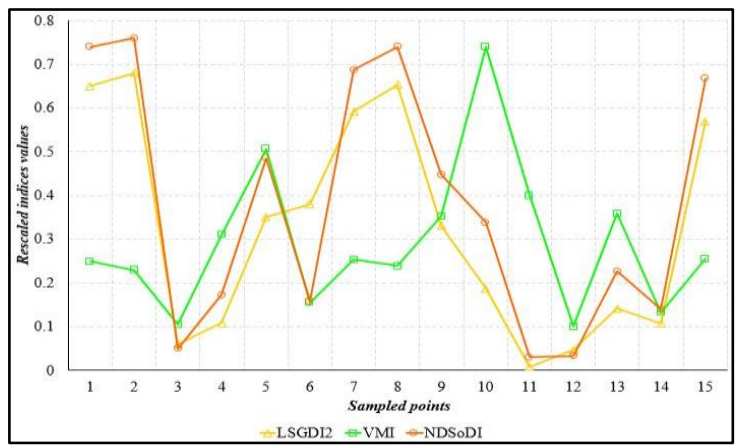

Figure13. LSGDI2, NDSoDI and VMI for April 2018 
Nevertheless, the LSGDI2 and NDSoDI curves have the same evolution. On fifteen (15) pixels sampled, fourteen (14) have exactly the same behaviour, i.e. $94 \%$. Moreover, a linear regression model (Figure 14) shows that NDSoDI contribute at $90 \%\left(\mathrm{R}^{2}=90.3\right.$ to the model, versus $10 \%\left(\mathrm{R}^{2}=0.07\right)$ for the VMI.

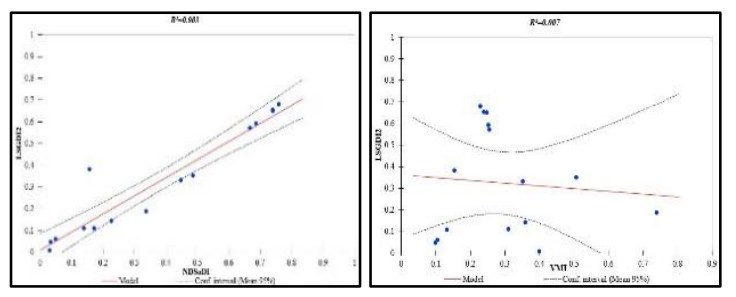

Figure 14. Regression of LSGDI by NDSoDI (left) and VMI (right)

\section{CONCLUSIONS}

The aim of this paper was to improve the LSGDI, formerly assessed as a normalized difference. The main methodology point has been to sum the vegetation moisture and the soil drought, both assessed through the VMI and the NDSoDI, to express the general drought. The proposed LSGDI2 appeared to be the square root of sum of squares of the two previous. The analysis of its results shows that its reflectance values in each class of drought is higher than MDPI1 and LSGDI.

\section{AKNOWLEDGEMENTS}

Authors are grateful to USGS for the satellite images freely available. They especially appreciate the support of StatsN'Maps management, for initiating and directing this work since its presentation to PECORA21/ISRSE38.

\section{REFERENCES}

Eslamian, S., Ostad-Ali-Askari, K., Singh, V.P., Dalezios, N.R., Ghane, M., Yihdego, Y., Matouq, M., 2017. A Review of Drought Indices. International Journal of Constructive Research in Civil Engineering, vol.3 (4), pp. 48-66.

Doi: http://dx.doi.org/10.20431/2454-8693.0304005

Gao, B., 1996. NDWI - a normalized difference water index for remote sensing of vegetation liquid water from space Remote Sensing of Environment 58: 257-266

Gbetkom, P.G., Gadal, S., El Aboudi, A., Ngandam Mfondoum, A.H., Mansour Badamassi, M. B., 2019. Combining spectral indices and statistics analysis to proposed a new risk of soil degradation method application to the Cameroonians shores of Lake Chad and its hinterland. Proceedings of Pecora 21/ISRSE 38, Baltimore, Maryland, USA. HAL Id: hal-02327627
Ghulam, A., Qin, Q., Kusky, T. and Li, Z., 2008. A reexamination of perpendicular drought indices.

International Journal of Remote Sensing 29 6037-6044. Doi: 10.1080/01431160802235811

Graham, S., 2000. Drought: The Creeping Disaster. Portions reprinted courtesy of the NOAA National Weather Service Office of Meteorology. https://earthobservatory.nasa.gov/features/DroughtFacts, last visited on November 5, 2019.

Gu, Y., Brown,J.F., Verdin, J.P. and Wardlow, B. 2007. A five-year analysis of MODIS NDVI and NDWI for grassland drought assessment over the central Great Plains of the United States, Geophys. Res. Lett., 34, L06407, doi:10.1029/2006GL029127.

Huete, A.R., 1988. A Soil-Adjusted Vegetation Index. Remote Sensing of Environment, 25:295-309 (1988)

Kogan F 1995 Application of vegetation index and brightness temperature for drought detection Advances in Space Research 15:91-100

Kogan F 1997 Global drought watch from space Bulletin of the American Meteorological Society 78:727-636

Li, Z. and Tan, D. 2014. A modified perpendicular drought index in NIR-Red reflectance space. ISRSE35, IOP Conf. Ser.: Earth Environ. Sci. Doi: 10.1088/1755$1315 / 17 / 1 / 012040$

Lobell, D. B., and G. P. Asner (2002), Moisture effects on soil reflectance, Soil Sci. Soc. Am. J., 66, 722- 727.

Ngandam Mfondoum, A.H., Etouna, J., Buji, K.N., Mvogo Moto, F.A., Noulaquape Deussieu, F.G., 2016. Assessment of Land Degradation Status and Its Impact in Arid and Semi-Arid Areas by Correlating Spectral and Principal Component Analysis Neo-Bands. International Journal of Advanced Remote Sensing and GIS, Vol.5 (2), 1539-1560. Doi: https://doi.org/10.23953/cloud.ijarsg.77

Ngandam Mfondoum, A.H., Gbetkom, P.G., 2019. Proposing a new drought assessment spectral model to anticipate desert fronts directions through sustainable agriculture expansion. Proceedings of Pecora 21/ISRSE 38, Baltimore, Maryland, USA.

http://pecora.asprs.org/wp-

content/uploads/2019/10/POS_004_Ngandam-

Mfondoum.pdf

Qin Q, Ghulam A, Zhu L, Wang L, Li J and Nan P 2008 Evaluation of MODIS derived perpendicular drought index for estimation of surface dryness over northwestern China. International Journal of Remote Sensing 29:1983-1995. 
Wang, L. and Qu, J.J., 2007. NMDI: A normalized multiband drought index for monitoring soil and vegetation moisture with satellite remote sensing. Geophys. Res. Lett., 34, L20405, doi: 10.1029/2007GL031021.

White, R.P., Nackoney, J., 2003. Drylands, people, and ecosystem goods and services: a web-Based Geospatial Analysis. World Resources Institute, 58P. 